\title{
Allá en el horizonte. El Estridentismo en Perspectiva Regional
}

\author{
Out There on the Horizon: Stridentism in Regional Perspective
}

\author{
Elissa Joy Rashkin
}

Resumen: El estridentismo, movimiento cultural de vanguardia de la década de 1920, tuvo su auge en la ciudad de Xalapa, Veracruz en el periodo de 1925 a 1927; sin embargo, los estudios del movimiento han dado poca atención a la relación entre ello y la particularidad de la historia regional. En este artículo se analiza el estridentismo como parte integral del proyecto modernizador de la administración del general Heriberto Jara, destacando algunos aspectos clave, como la urbanización, el deporte, la comunicación y algunos conflictos políticos, particularmente el petrolero, trascendente tanto a nivel regional como nacional y transnacional.

Palabras clave: estridentismo, Manuel Maples Arce, Heriberto Jara, Germán List Arzubide, movimiento estridentista.

Abstract: Stridentism (estridentismo), Mexican avant-garde cultural movement of the 1920s, reached its peak of activity in the city of Xalapa, Veracruz in the years 1925-1927. Studies of the movement, however, have paid little attention to the relationship between it and the specificity of the region's history. This article examines Stridentism as an integral part of the modernizing project spearheaded by Governor Heriberto Jara, and highlights several aspects, as urbanization, sports and communications as well as key political conflicts, in particular, the nationally and internationally transcendent issue of the oil industry.

Keywords: stridentism, Manuel Maples Arce, Heriberto Jara, Germán List Arzubide, stridentist movement.

Elissa Joy Rashkin, doctora en estudios de la comunicación por la Universidad de Iowa, Estados Unidos. Profesora-investigadora en la Universidad Veracruzana, México. Temas de especialización: historia cultural mexicana del siglo XX. Correo electrónico: erashkin@uv.mx, elissara@yahoo.com.
Enviado a dictamen: 21 de enero de 2014. Aprobación: 25 de marzo de 2014.

Revisiones: 1 . 
$\mathrm{E}$ estridentismo, uno de los movimientos de vanguardia de más larga vida y de mayor producción cultural en América Latina durante la década de 1920, ha sido estudiado - cuando no olvidado por completo- principalmente dentro del campo de la literatura mexicana. Este enfoque tiene sentido si recordamos que los estridentistas que se identificaron como tales, los que escribieron los artículos definitorios y firmaron los manifiestos, eran poetas, ensayistas y escritores de ficción experimental. No obstante, la producción gráfica del movimiento ha surgido en los últimos años como otro enfoque central de investigación, estrechamente relacionado con el replanteamiento antioficialista de la historia del arte en México y con los estudios del urbanismo y la modernidad. Conforme se van descubriendo y rescatando muchos elementos perdidos del movimiento, la generación actual de investigadores, descartando viejos prejuicios emanados de rivalidades literarias ya sin importancia, reivindica y reconoce las dimensiones del estridentismo como movimiento cultural multifacético.

En este contexto, consideramos pertinente explorar la vanguardia estridentista desde la perspectiva de la historia regional, enfocándonos sobre sus actividades en el estado de Veracruz durante el breve, pero fértil, periodo de 1925 a 1927. Esta perspectiva rechaza el centralismo implícito en muchos de los estudios del movimiento - escritos desde la ciudad de México- para enfocarse en la relación entre la historia del movimiento estridentista y la historia de la región durante el gobierno del general Heriberto Jara Corona (1924-1927), considerando el estridentismo como parte integral del proyecto modernizador de la administración jarista en la ciudad de Xalapa durante la década de 1920. Siendo ésta una historia compleja como todas, abarcamos solamente algunos aspectos: la urbanización, el deporte, la comunicación y algunos conflictos políticos, particularmente el petrolero, trascendente tanto a nivel regional, como nacional y transnacional. Pero primero es preciso repasar, a grandes rasgos, los orígenes y la trayectoria del movimiento, así como su llegada al estado de Veracruz en 1925.

\section{La llegada de los estridentistas a Xalapa}

Al concluir la etapa bélica de la Revolución mexicana en 1920, se inició una época de renovación en el país que abarcó diversos campos del quehacer cultural, como educación, teatro, danza, arqueología, artes plásticas o literatura, entre otros. Al mismo tiempo, florecieron los movimientos sociales, de forma sobresaliente los de obreros y campesinos; pero también el feminismo, el de los inquilinos y otros, que reivindicaron los ideales revolucionarios de libertad y justicia social. El poder convocatorio de estos movimientos reflejaba tanto las condiciones de desigualdad que aún perduraban después de la Revolución, como el empoderamiento de los sectores oprimidos y la formación de nuevas identidades colectivas.

En este contexto, el estridentismo surgió en 1921 como movimiento artístico de vanguardia que rompía con los cánones estéticos establecidos, a la vez que promovía ideales sociales progresistas. Para Manuel Maples Arce, fundador del movimiento y entonces estudiante en la Escuela Libre de Derecho, el ambiente cultural del país estaba en desfase con los acontecimientos nacionales y también con las vanguardias internacionales, de las cuales le habían llegado algunas publicaciones y noticias a través de la prensa. Criticaba lo que consideraba la persistencia de las manifestaciones culturales del porfiriato - elitistas y conservadoras- en la nueva sociedad posrevolucionaria. En su manifiesto fundacional titulado Actual no. 1, hoja de vanguardia, anunciaba lo siguiente:

Con este vocablo dorado: estridentismo, hago una transcripción de los rótulos dadá, que están hechos de nada, para combatir la "nada oficial de libros, exposiciones y teatro". En síntesis una fuerza radical opuesta contra el conservatismo solidario de una colectividad anquilosada (Maples, 1921: 273).

A partir de esellamadoinicial, se unieron al estridentismo numerosos intelectuales que compartían inquietudes creativas y una actitud iconoclasta ante lo tradicional y lo establecido: los escritores Germán List Arzubide, 
Arqueles Vela, Salvador Gallardo y Luis Quintanilla Kyn Taniya; los pintores Ramón Alva de la Canal, Jean Charlot, Leopoldo Méndez, Fermín Revueltas y Rafael Sala; los escultores Guillermo Ruiz y Germán Cueto; y, como colaboradores cercanos, el pintor Diego Rivera, los fotógrafos Tina Modotti y Edward Weston, y otros más, entre ellos el periodista Carlos Noriega Hope, editor del semanario El Universal Ilustrado, donde los estridentistas encontraron un foro abierto y acogedor.

En 1922, los estridentistas lanzaron un segundo manifiesto, desde la ciudad de Puebla, que causó gran escándalo por su irreverencia hacia la historia oficial y hacia algunas conocidas figuras de la cultura local. De 1922 a 1925 editaron libros de poesía y ficción, además de dos números más de Actual y tres de Irradiador, revista dirigida por Maples Arce y Revueltas en los últimos meses de 1923; se reunían en un café que bautizaron como el Café de Nadie, donde en abril de 1924 organizaron una "tarde estridentista" con lecturas en voz alta, música y exposiciones de obras plásticas. También participaron, a través de Luis Quintanilla, en el Teatro Mexicano del Murciélago (1924), con obras innovadoras que combinaban la reivindicación de tradiciones populares con episodios sobre aspectos de la ciudad moderna. En esos años el término "estridentista" entró al lexicón nacional como sinónimo de "futurista", vocablo empleado para referirse a cualquier fenómeno novedoso, insólito e incomprensible.

¿Cómo y por quéllegaron los estridentistas a Xalapa? A pesar de sus años de trabajo creativo y la notoriedad ganada como resultado de ello, el grupo - constituido en gran parte por jóvenes de provincia, como el poblano List Arzubide, el guatemalteco-chiapaneco Vela, el potosino Gallardo y el propio Maples Arce, originario de Papantla, que pasó su infancia en Tuxpan y su juventud en el puerto de Veracruz - encontraba en la ciudad de México un ambiente poco hospitalario. Después de diez años de guerra civil, escaseaban los recursos para la cultura; el único mecenas era el Estado mismo, y mientras los muralistas encontraron un generoso patrón en el secretario de educación José Vasconcelos, la suerte de los estridentistas fue diferente. Vasconcelos ya había entablado lazos con otro - menos ruidoso - grupo de jóvenes escritores, los futuros contemporáneos, quienes ya ocupaban puestos en el gobierno, mientras los estridentistas apenas sostenían sus proyectos editoriales y culturales de manera independiente.

Por ello, al graduarse en la Escuela Libre de Derecho a principios de 1925, Maples Arce decidió regresar a su estado natal en busca de trabajo, armado con una recomendación del eminente político revolucionario Alfonso Cravioto, constituyente, senador, escritor, y además amigo de su padre, el también abogado y poeta Manuel Maples. Llevó dicha recomendación al gobernador recién electo, el general Heriberto Jara, y pronto encontró empleo como juez de primera instancia en Xalapa. Los otros estridentistas, al principio, entraron en una especie de choque: iqué será del movimiento?, se preguntaban en sus reuniones y correspondencia, ya que su líder fundador se había convertido en un burócrata, empleado menor de un gobierno estatal de provincia. A pesar de sus dudas, List Arzubide siguió a su amigo a Xalapa para trabajar como su secretario particular, ambos garabateando sus versos en los márgenes de los expedientes judiciales. Y pronto vino el golpe de suerte, tal como se puede leer en ElDictamen el 7 de enero de 1926:

Hoy fue nombrado Secretario General del Gobierno del Estado, el licenciado Manuel Maples Arce, que desempeñaba el puesto de juez de primera instancia de esta ciudad. Hoy mismo recibió el licenciado Arce la Secretaría por entrega que le hizo el oficial primero, señor Raymundo Mancisidor, quien desempeñaba las funciones de Secretario desde septiembre ("Nuevo Secretario General de Gobierno", 1926: 3).

Con el insólito nombramiento del joven poeta para uno de los puestos más importantes del gobierno jarista, se inició lo que podemos considerar la época dorada del estridentismo, en la que el movimiento se transformó a raíz de sus nuevas relaciones políticas y a la vez logróincidir en su entorno, lo que produjo una especie de fusión entre el arte vanguardista por un ladoy, por otro, el gobierno que se presentabaigualmente vanguardista en su ideología, obras yprácticas políticas. Enfebrero, List Arzubide escribió una cartaa Gallardoen la que captabala emoción delmomento: 
Comenzaré por decirte que vivo en la segunda de Benito Juárez número 10 de esta ciudad equilibrista y estridente, apuntalada con mis risas rebeldes [...] Según sé, Maples está a punto de conseguirte una chamba colosal y si es eso, querrá decir que nos reuniremos aquí en el Estado Mayor y vamos a hacer temblar el mundo. [...] Voy a ser el director de una revista que se llamará Horizonte y en la cual vamos a decir muchas cosas fuertes, espero poder publicar pronto en ella algo tuyo (López, 1998: 248).

Además de Gallardo, quien encontró la prometida "chamba colosal" en el departamento de salubridad pública, los líderes estridentistas congregaron también a Leopoldo Méndez y Ramón Alva de la Canal, quienes se hicieron ilustradores de la mencionada revista Horizonte, y los escritores Enrique Barreiro Tablada, Eduardo Colín - convocado a dirigir la Escuela PreparatoriaMiguel Aguillón Guzmán y, de manera ocasional, Arqueles Vela y Germán Cueto. A este grupo, en Xalapa se sumaron otros participantes, como el abogado y novelista duranguense Xavier Icaza, el médico y poeta Ignacio Millán, y estudiantes como Lorenzo Turrent Rozas, Miguel Bustos Cerecedo y otros jóvenes quienes, en años posteriores, editarían revistas literarias como Momento, Simiente, Noviembre y Ruta, publicaciones que, de cierta manera, heredaron el proyecto estridentista y lo ajustaron al ambiente militante de la década de 1930 (Bustos, 1983: 260-286; Turrent, 1973: 210-212 y 224-230).

\section{$\mathrm{Al}$ “estridentizar" el estado}

La alianza con el gobierno jarista dio a los estridentistas gran visibilidad tanto en la prensa regional, como en la legislatura estatal, donde los diputados de oposición a veces atacaron al gobernador acusándolo de "estridentizar" el estado. De hecho, Maples Arce y los estridentistas utilizaron su posición para intervenir en la educación pública, realizar eventos culturales y, sobre todo, avanzar en su proyecto editorial. En abril de 1926 publicaron el primer número de Horizonte, revista cultural en la que coexistían obras de naturaleza muy ecléctica: arte y literatura moderna y estridentista, reportajes sobre las labores del gobierno, promoción turística de los atractivos de Veracruz, traducciones de autores extranjeros, artículos didácticos sobre agricultura e ingeniería mecánica y comentarios sociales. El mismo año editaron Magnavoz 1926, una especie de guión teatral subtitulado Discurso mexicano, de Xavier Icaza, y la obra El movimiento estridentista, de List Arzubide, crónica vanguardista del movimiento y de sus actores y momentos clave desde 1921.

Elaño siguiente, 1927, publicaron los Poemas interdictos de Maples Arce, además de otro libro suyo, El movimiento socialen Veracruz, basado en su discurso del l de mayo de ese año; luego la obra de List Arzubide titulada Emiliano Zapata: exaltación, muy probablemente el primer libro serio sobre el líder y mártir del agrarismo mexicano; y El Café de Nadie, recopilación de tres novelas cortas de Arqueles Vela. Por otra parte, en la colección Biblioteca Popular, publicaron El imperio de los Estados Unidos y otros ensayos, de Rafael Nieto, una edición conmemorativa de la Fábula de Polifemo y Galatea de Góngora, y la primera edición en forma de libro de Los de abajo, de Mariano Azuela. Además de estos libros, produjeron folletos, carteles y suplementos musicales de la revista Horizonte que reflejaban tanto los gustos cosmopolitas de la época, como las influencias regionales, por ejemplo, el danzón; en algún momento también emprendieron un trabajo de recopilación de sones jarochos de Medellín, proyecto que, a pesar de haber sido terminado e impreso, con diseño gráfico de Alva de la Canal, desafortunadamente se perdió cuando el cuartelazo de septiembre de 1927 derrocó el gobierno estatal, y con ello, el movimiento; fue ésta una de las muchas lamentables pérdidas o daños colaterales de la historia de la consolidación del poder posrevolucionario.

La diversidad de los temas y títulos mencionados nos indica que la tenue división que los multifacéticos estridentistas habían sostenido entre arte y participación política, o, en el concepto de List Arzubide, entre "batalla social" y "nueva estética", se iba transformando a través de la alianza con el Estado en una suerte de aventura híbrida en la que cabían vocaciones didácticas, políticas y creativas. Surgió entre ellos la idea del "revolucionario integral", que militaba tanto 
en las filas de los movimientos sociales, como en la lucha por la transformación literaria y artística. ${ }^{1}$ Todo eso, por supuesto, sostenido por el gasto público: los recursos de los Talleres Gráficos del Estado, el sueldo de Maples Arce y los modestos salarios que ganaban los demás integrantes del grupo dando clases en la Escuela Preparatoria, la Normal o la de Artes y Oficios. Ya no era posible sostener lo que había escrito Maples en Actual en 1921, que "mi locura no está en los presupuestos", pues es claro que el proyecto de los estridentistas en Xalapa ya estaba totalmente integrado con el del Estado posrevolucionario a nivel local.

\section{El gobierno del general Jara: ¿proyecto estridentista?}

¿En qué consistía este proyecto impulsado por el gobernador y sus colaboradores, y qué papel jugó el estridentismo en ello? En términos generales, podemos hablar de un proyecto modernizador, en el sentido de la modernidad y también de la modernización. La modernidad se reflejaba en elementos como la defensa de los derechos de los trabajadores; la centralidad de la educación pública, gratuita, racional, laica y activa; el rechazo al dominio ideológico de la Iglesia; y, en general, un programa de corte moderadamente socialista que asumía la posibilidad de racionalizar la sociedad a través de planificación y reformas legislativas, y de controlar, si no eliminar, los intereses capitalistas en beneficio de la mayoría. Este racionalismo utópico — si cabe la contradicción - también era fundamental en el compromiso jarista-estridentista con la modernización en todos sus aspectos: la fe absoluta en los avances de la ciencia y la tecnología, manantiales pródigos de un futuro mejor.

El impulso modernizador del gobierno de Jara es evidente, primero, en su programa de urbanización. Cabe señalar que en este proceso no se puede considerar solamente el resultado de una iniciativa desde arriba; al contrario, a Xalapa como a muchas otras ciudades pequeñas, en ese momento, la modernización había llegado sola, manifestándose en el incremento de automóviles, las nuevas tecnologías de comunicación, las nuevas necesidades creadas por la cultura de consumo y en el crecimiento urbano en general, producto en parte de la inestabilidad en el campo que provocaba el desplazamiento de una parte de la población rural hacia las ciudades.

Sin embargo, la modernización de la ciudad fue una de las metas de la administración jarista, y por ello se ampliaron y pavimentaron calles, se expandió la instalación de alumbramiento eléctrico, se construyó un nuevo hotel para estimular el turismo y acomodar las visitas de empresarios, se otorgó a la compañía petrolera el Águila el permiso de abrir un sitio de automóviles en el mero centro de la ciudad, a un costado de la catedral, y se desarrolló una ambiciosa propuesta de planificación urbana que incluía la construcción de zonas mixtas - residenciales y comerciales - con espacios verdes y vivienda cómoda y accesible a todos los sectores de la sociedad.

El estadio, con su uso innovador del cemento que permitía el rechazo de los modelos arquitectónicos neoclásicos y la armonización de la estructura con su entorno natural, fue la obra emblemática de la administración, obra que, si bien precedió a la incorporación del grupo estridentista en el gobierno de Jara, indudablemente compartía su espíritu vanguardista. En el primer número de la revista Horizonte, List Arzubide exaltó el estadio no tanto por su diseño novedoso, sino por su función cívica; lo consideraba un espacio que pertenecía a todos y que democráticamente ofrecía a los estudiantes, obreros, empleados, maestros, soldados y mujeres un nuevo espacio simbólico, "altar para una vida mejor y más fecunda de hombres buenos y fuertes" (1926a: 8). Maples Arce, por su parte, escribió en el tercer número de Horizonte sobre "La estética del sidero-cemento", artículo en el que habló de la arquitectura en el contexto de lo queél llamaba la "tendencia hacia la universalidad" y que ahora llamaríamos la globalización, un mundo donde las condiciones locales ya no determinaban las formas ni los métodos de construcción. Argumentó la importancia de la creatividad humana ante las posibilidades plásticas del cemento, criticó los usos limitados de éste en México hasta entonces, y observó que "La posición subjetiva que 
el espíritu humano ocupa frente al paisaje de la realidad histórica, determina la dirección de sus objetivaciones paradigmáticas" (1926: 9-11). Es decir, la tecnología por sí sola no es avance, sino que lo es solamente a través de los actos del hombre innovador y visionario.

Curiosamente, la mayoría de los comentarios publicados sobre el estadio, tanto en la prensa estridentista como en la convencional, hablaban más de su forma que de su función; además, a partir de su inauguración en septiembre de 1925, el estadio aparecía en el récord histórico — prensa, fotografías, etcétera- más como escenario de eventos políticos, cívicos y culturales, que como arena deportiva. Sin embargo, la promoción del deporte fue otra faceta importante del programa modernizador del Estado y de los estridentistas, pues después de los muchos años de guerra civil, con sus frecuentes episodios de carestía, epidemias y hambre, nada resultaba más atractivo para un gobierno reformista que la innegable salubridad de la actividad física. Además, la aún no tan lejana introducción de juegos como el beisbol y el futbol en la entidad, muchas veces sostenidos por sindicatos, escuelas obreras y otras agrupaciones progresistas, dio al deporte el aura luminosa de la modernidad.

Por ello, al separarse el Departamento del Trabajo del antiguo y sobrecargado Departamento de Fomento, Agricultura y Trabajo, una de sus actividades, además de mediar conflictos laborales y en caso de necesidad expropiar las empresas y entregarlas a sus trabajadores -como pasó notablemente con el ferrocarril de Xalapa a Teocelo y la planta de luz, ambos antes en manos de estadounidenses - , era atender las solicitudes obreras en asuntos relacionados con el deporte, en especial apoyándolos en la formación de equipos de beisbol. En las páginas de Horizonte, Celestino Herrera escribió: "El deporte en sus múltiples formas, ya sea atletismo, natación o alguno de los juegos mayores como se llama al Foot, al Base y al Basket-Ball, es eminentemente educativo y de un inestimable valor en nuestra época. [...] La práctica de los deportes debe extenderse más ampliamente en nuestro país; [...] seguramente será uno de los factores más importantes de la reconstrucción moral y física de nuestra Patria" (Herrera, 1926a: 40).
En otro número de la revista, el mismo autor hablaba específicamente sobre la vida deportiva en Xalapa: "Gracias al decidido apoyo prestado por el entusiasta Gobernador del Estado, el deporte ha alcanzado un desarrollo notable en la ciudad de Xalapa. La construcción de su hermosísimo Estadio vino a intensificar notablemente las prácticas deportivas, interesándose la juventud en estas actividades por contar con un local debidamente apropiado para ellas" (Herrera, 1926b: 37). Herrera destacaba el beisbol como el deporte que atraía el mayor número de aficionados; notaba que el club local Ocampo, "formado a iniciativa del Gral. Jara y llevando el nombre de la Brigada que fue a su mando, es el sostenedor de la afición por el Rey de los Deportes y cuenta con un espléndido récord que seguramente no tiene comparación con ninguno, de otros equipos de la República" (1926b: 37). Cabe mencionar que la Liga Mexicana de Beisbol fue fundada apenas en 1925, con fuerte influencia cubana. Sus primeros partidos se jugaron en el puerto de Veracruz y, según la página web de la liga, el equipo campeón en 1926 fue precisamente el Ocampo de Xalapa, cuyo manager fue nada menos que el escritor y político revolucionario José Mancisidor.

Se trata de una historia que obviamente da para efectuar investigaciones más profundas. Pero, regresando a Celestino Herrera, en su artículo menciona también las actividades del Club Deportivo Jara; del Jalapa Tennis Club, donde posiblemente jugaba Maples Arce, según cuenta en su autobiografía titulada Soberana juventud; ${ }^{2}$ y de la Escuela Preparatoria, donde el deporte preferido de estudiantes de ambos sexos era el basket, en el cual la escuela había ganado el campeonato regional. También existían equipos de basquetbol y otros deportes en la Escuela Normal, la Industrial de Señoritas y las escuelas regidas por el Departamento Universitario del Estado. El deporte y la educación física, entonces, formaron parte integral del programa educativo del estado, y en ello participaron maestros e intelectuales, quienes lo vieron no sólo como opción recreativa sana y divertida, sino también como uno de los medios para lograr la transformación profunda de la sociedad. 


\section{Comunicación y modernización}

Otra área importante de intervención estatal y estridentista se desplegó en los medios de comunicación, piedra angular de la sociedad moderna en diversos aspectos, desde la educación pública hasta la cultura de consumo capitalista, además de desempeñar las funciones de información y entretenimiento, expresión de ideas y formación de la opinión pública. Ya hemos mencionado, en este sentido, las publicaciones estridentistas, en especial Horizonte, que se anunciaba como "revista mensual de actividad contemporánea". Pero también se puede hablar de los emergentes medios audiovisuales, es decir, la radio y el cine.

La radio, en este sentido, fue la más novedosa, ya que la primera estación comercial de radio en México, la de la casa Azcárraga y El Universal Ilustrado, se había inaugurado apenas en 1923, justamente con la lectura de un poema estridentista de Manuel Maples Arce, seguido por un programa de música clásica y popular. En Xalapa, el gobierno de Heriberto Jara estableció una radiodifusora cultural, ubicada cerca del estadio, donde hoy en día está ubicada la rectoría de la Universidad Veracruzana. En la programación participaban con frecuencia List Arzubide y otros miembros del grupo Horizonte. Aunque no quedan registros del contenido especifico de sus transmisiones, la estación xalapeña fue pionera en el uso de la radio para fines culturales y educativos, proyecto que algunos de los estridentistas continuarían después en Radio Educación y otros foros radiofónicos nacionales (List Arzubide, en Wilkie y Monzón, 2001: 254).

En cuanto al cine, hemos encontrado huellas interesantes de algunos proyectos ligados con, o patrocinados por, el estado. Aunque el cine veracruzano de la época venía esencialmente de la zona industrial de Orizaba, ${ }^{3}$ el gobierno estatal fomentaba la producción cinematográfica en la capital por medio de su departamento fotográfico, el cual, según el informe que presentó el gobernador el 5 de mayo de 1926, llevaba filmadas más de diez películas y ya estaba filmando "otra de arte nacional denominada 'Ixtaccihuatl"' (Jara, 1926: 5898). Por otra parte, el fotógrafo Atanasio D. Vázquez, cuyas imágenes del campo y de la capital son piezas fundamentales de la memoria visual del agrarismo y la vida política de la época, también realizó películas que, según las descripciones publicadas en la prensa, documentaban festividades de la comunidad, actos cívicos y obras públicas, principalmente el estadio, que Vázquez había filmado desde el proceso de construcción. El 24 de julio de 1927, apenas dos meses antes de la caída del gobierno jarista, Vázquez inició una gira cinematográfica estatal con un programa de sus películas en el Teatro Lerdo. El evento fue presentado por List Arzubide y, durante el intermedio, el público se entretuvo escuchando versos recitados por Leobardo González, compositor y jefe del Departamento de Educación Estética Popular ("Jira cinematográfica", 1927: 5).

El 4 de agosto, El Dictamen reportó que "el conocido cinematografista jalapeño" había regresado de su gira, con planes de partir nuevamente y llevar sus películas a otras regiones del estado ("Exhibición de películas", 1927: 5). Dos meses después, Vázquez se encontraba presentando sus películas en Tampico cuando recibió las noticias del violento desafuero del gobernador, a quien mandó un telegrama de apoyo:

Permítome ratificarle mi más sincera adhesión elevando enérgica protesta contra actos diputados venales arrojáronlo Gobierno que pueblo designóle. Mañana paso películas su grandiosa obra en Cine Isabel y si no ordena contrario salgo Monterrey ponerme ordenes Gral. Sáenz efecto combatir infidencia. Salúdolo muy resptte. ${ }^{4}$

Hasta la fecha no se sabe qué pasó con la carrera cinematográfica de Vázquez, y tampoco se han localizado sus filmaciones. Sin embargo, Aurelio de los Reyes mencionaba en su Filmografía del cine mudo mexicano que una película titulada Jalapa se estrenó en el Salón Victoria en septiembre de 1925, pocos días antes de la inauguración del estadio por el presidente Plutarco Elías Calles. Una de las personas que aparecen en la película es "la señorita Rolland", pariente, suponemos, del ingeniero Modesto C. Rolland, arquitecto del mismo 
estadio (De los Reyes, 2000: 36). La descripción hace pensar que se trata de una compilación de los rollos filmados por Vázquez, pero, ante la falta de evidencia, por el momento el tema queda pendiente para futuras investigaciones. ${ }^{5}$

¿Cómo se pueden caracterizar o imaginar los contenidos ideológicos transmitidos a través de estos medios? Aunque a los críticos del gobernador les gustaba tacharlo de bolchevique o jacobino, en realidad el programa jarista reflejaba, en el fondo, los ideales humanistas de la modernidad. Por más intervencionista que fueran su visión del Estado y las prácticas de su gobierno, Jara no proponía la abolición del capitalismo, sino la amortiguación de sus efectos - la desigualdad económica y social - por medio de la regulación y la negociación. También, como otros gobernantes radicales de la época -Cándido Aguilar y Adalberto Tejeda en Veracruz, Felipe Carrillo Puerto en Yucatán, Francisco Mújica en Michoacán, etcétera-, apostó por la razón y por la capacidad del ser humano de cambiary mejorar sus condiciones de vida a través de la educación, la organización y la ley; es decir, considerando la legislación como una herramienta de ingeniería social.

\section{El conflicto político, o los dilemas de Panchito Chapopote}

Claro es que, en la complicada vida real, había mucha distancia entre los ideales y la práctica; por ello Xavier Icaza, en su fascinante texto vanguardista Magnavoz 1926, escribió la siguiente escena, en la cual una enorme bocina emerge de las entrañas del Pico de Orizaba y difunde la voz de Lenin hacia el horizonte:

Sones de la Internacional. Hoz y martillo. Salud y Revolución Social.

Veracruz no se limita a escuchar. No sabe hacerlo. No medita. Por sus venas corre el fuego del trópico. Veracruz todo lo traduce en acción. Veracruz obedece el discurso, sin discernirlo bien. Inventa leyes, leyes, leyes. Veracruz es la legisladora de México: Ley de Trabajo; Ley del Inquilinato; Proyectos de
Legislación Petrolera; Repartimiento de Tierras; Arrendamiento Obligatorio de Tierras. Descanso Dominical. Participación en las Utilidades. Ley del Candado. Ley del Hambre, y agitación, revolución, agitación [...] (Icaza, 1926). ${ }^{6}$

En el momento de escribir este texto, Icaza era empleado de la compañía petrolera El Águila, la cual estaba metida en un sinnúmero de conflictos laborales y legales, conflictos en los que el gobierno casi siempre apoyaba la posición de los trabajadores en contra de la compañía. Además, ante la situación cada vez más desesperada del erario estatal, que ya estaba conllevando retrasos en el pago de sueldos y otros problemas graves para los empleados públicos, Jara optó por la estrategia de insistir en que las compañías que explotaban el subsuelo veracruzano pagaran las debidas regalías al estado, no sólo a la federación.

La posición de Jara le provocó conflictos con el gobierno de Calles ya que éste estaba precisamente en aquel momento intentando aplacar las preocupaciones de los inversionistas extranjeros en el país a través de negociaciones diplomáticas. Esta situación, junto con otras relacionadas más con el faccionalismo y el ya mencionado retraso extremo en el debido pago a los trabajadores del estado, finalmente provocó la intervención federal y el derrocamiento del gobierno de Jara en septiembre de 1927, aunque la valentía de éste sería validada posteriormente durante la expropiación petrolera de 1938, llevada a cabo por el presidente Lázaro Cárdenas, jefe de operaciones militares en la Huasteca durante los años veinte $y$, cabe mencionar, aliado en ese entonces de Jara en su lucha contra las petroleras, postura que quizás prefigura su rompimiento con Calles, el jefe máximo de la Revolución, en la década siguiente.

Regresando a Xavier Icaza, es interesante notar que, doce años después de Magnavoz 1926, el ex apoderado legal de la compañía El Águila fue integrante de la misma Suprema Corte de la Nación que ratificó la expropiación petrolera, además de profesor fundador de la Universidad Obrera y entusiasta exponente de las doctrinas cardenistas y socialistas de la época. En 1926, 
sin embargo, las batallas constantes con los sindicatos de la Confederación Regional Obrera Mexicana (CROM) y con el gobierno le fastidiaban, como expresó en su correspondencia con Alfonso Reyes y otros viejos amigos. Su integración a la vida social de la élite de Xalapa a través de su matrimonio con Ana Güido seguramente contribuyó al desarrollo de una perspectiva no del todo compartida por sus camaradas estridentistas; de hecho, fue precisamente Maples Arce, como secretario de gobierno y gobernador interino cuando el general Jara salía de viaje, quien formuló la posición del gobierno frente a las empresas petroleras y defendió la acción sindical. A pesar de esas diferencias, Icaza colaboró en Horizonte en dos ocasiones y escribió, además de Magnavoz, la novela Panchito Chapopote. Retablo tropical o relación de un extraordinario suceso de la heroica Veracruz, redactada en Xalapa en 1926 aunque, debido a los súbitos cambios políticos en la entidad, no fue publicada sino hasta dos años después en la ciudad de México. ${ }^{7}$

Panchito Chapopote narra las aventuras del personaje del título, vecino del pueblo de Tepetate en la Huasteca y heredero de unas tierras que no sirven para sembrar debido a la abundancia de chapopote. Un día, llega un grupo de hombres de negocios estadounidenses, seguido por otro de ingleses, ambos dispuestos a pagar bien por las tierras estériles de Panchito, quien pronto va al puerto a disfrutar su nueva riqueza. Cuando regresa a Tepetate, en vísperas de la revolución maderista, todo ha cambiado; el humilde pueblo campesino ya se ha convertido en uno de los company towns de los campos petroleros, con lunch counters estilo yanqui y "hoteles más caros que el Ritz". El objetivo de su regreso es casarse con Amalia María, muchacha que, aunque ama a otro, no tiene más opción que ceder ante el poder económico de su rico pretendiente. Pero después de la boda estalla la Revolución, representada por Icaza de manera paródica:

iPif! iPaf! iPum! iPam! Cañonazos. La bola se pone caliente. La bola ha llegado a Tepetate. iDe veras hay revolución!
Diez mil, veinte mil, cincuenta mil cartuchos se disparan. Las ametralladoras se embalan. Los cañones carecen de telémetro. Cincuenta mil cartuchos disparados. iYa cayó Tepetate! Se levanta el campo: dos muertos, tres heridos (Icaza, 1928: 74).

Panchito, después de haber sido obligado a otorgar un préstamo forzoso a los revolucionarios, muere en el conflicto, aunque Icaza deja claro que es él, el autor, quien lo mata; "Muérete ya, Panchito. Ya no te necesito. Con tu boda y tu plagio, tu razón de ser ha terminado. Tu existencia no tiene justificación" (Icaza, 1928: 76). A pesar de sus protestas, el protagonista muere y Tepetate, junto con el resto de México, sale por fin del caos y la confusión de la época revolucionaria. La viuda de Panchito se casa con su amor verdadero y en territorio veracruzano todo vuelve a ser alegría, huapango, rumba y danzón.

Sin detenernos más en esta extraordinaria novela, con sus divertidas ilustraciones realizadas por Ramón Alva de la Canal, propongo que el retrato sintético que ofrece del conflicto petrolero en el porfiriato hasta la Revolución encuentra una suerte de continuación en algunos documentos del archivo de Heriberto Jara, que muestran los esfuerzos de éste por poner fin a la explotación desmedida del subsuelo sin ningún beneficio para el pueblo veracruzano. Dichos conflictos giraban alrededor de las tierras petroleras que, al morir sus dueños, quedaron sin heredero. En numerosos casos, los hábiles apoderados de las compañías extranjeras lograron presentar "familiares" hasta entonces desconocidos del difunto para quedarse con el rico botín; Jara, en cambio, argumentaba que las tierras sin dueño quedaban en propiedad del estado, suscitando por ello acaloradas batallas con el Secretario de Industria y Comercio, Luis N. Morones, las cuales sin duda contribuyeron al desafuero de Jara un año antes de que concluyera su mandato. Aunque ni Icaza ni el grupo de Horizonte tocaban estos delicados temas abiertamente en sus publicaciones, no cabe duda de que el asunto petrolero permeaba el ambiente de la época de muchas maneras, desde las luchas obreras y disputas sobre la extracción del subsuelo, hasta el uso del automóvily las 
transformaciones que éste implicaba en el paisaje y en la vida cotidiana de las ciudades.

\section{Reflexión final: el automóvil en la catedral}

Para concluir, consideremos una imagen emblemática, aunque a la vez apócrifa, del estridentismo en Xalapa. En algún momento de los años veinte, alguien sube un automóvil Ford a las escaleras de la catedral, y luego baja manejando; este acto de performance queda documentado en fotografías sin fecha ni autor, pero no por eso menos espectaculares. En el libro Imágenes de Xalapa a principios del siglo XX, Adriana Naveda Chávez-Hita (1986) identifica al intrépido motorista como Othón M. Vélez, nombre que no he visto mencionado en conexión con los estridentistas. Sin embargo, la familia de List Arzubide recordaba la versión del evento contada por su padre, en la cual no quedaba duda de la afiliación estridentista del acto. Por otra parte, en su novela histórica Los años con Laura Díaz (1999), Carlos Fuentes atribuye el performance automovilístico a un Xavier Icaza ficticio, personaje que representa el estridentismo en la novela, y lo explica como un gesto audaz realizado con el fin de impresionar a la joven Ana Güido mientras ella asistía a misa en la catedral.

De hecho, una de las fotos del evento, encontrada en un puesto callejero y que aún no hemos podido localizar en los acervos oficiales, nos permite verificar la presencia de no uno, sino dos hombres en el carro, aunque desafortunadamente la foto no tiene suficiente claridad como para identificarlos. Por ahora, la verdadera historia de este acto "performático" permanece en las sombras. No obstante, el no conocer los detalles del evento no quita el valor simbólico de la imagen, pues en ella se resume gráfica y sintéticamente el proyecto modernizador emprendido por los estridentistas, primero en la esfera literaria y cultural, y luego, a través de su colaboración con el gobierno jarista, en el escenario más amplio de las políticas públicas y los imaginarios sociales.

La velocidad del carro, que implica movimiento en el tiempo y el espacio, reemplaza la solemnidad imponente e inmóvil de la catedral. Se sustituye la religión por la fe infinita en las bondades de la tecnología y la ciencia moderna, y en las caras de los dos hombres, rodando sobre los desgastados escalones del caduco pasado, vemos la deslumbrante emoción de un presente agitado, dinámico y maravilloso, las promesas de un futuro mejor... y, en las palabras poéticas del estridentista Salvador Gallardo (1925), "un bostezo fugaz de gasolina".

\section{Notas}

1 "Pienso que soy un revolucionario integral, un revolucionario de la forma poética y también en la cosa política" (List Arzubide, en Wilkie y Monzón, 2001: 249).

2 "En las mañanas, después de jugar al tenis o montar a caballo, llegaba yo a Palacio y comenzaba a despachar con los jefes de departamento [...]" (Maples, 1967: 204).

${ }^{3}$ Esto se debía a la comunicación vial de la zona con el centro del país, a la relación entre las tecnologías de producción y las de comunicación — de hecho las primeras vistas cinematográficas captaron escenas de las fábricas y sus trabajadores- y, por otra parte, a la gran población obrera que en sus pocas horas de ocio se convirtió en el público de los espectáculos, entre ellos el cine (Ortiz, 2001).

${ }^{4}$ Centro de Estudios sobre la Universidad, Fondo Heriberto Jara Corona, 1927, caja 11, exp. 432, f. 6448.

${ }^{5}$ Cabe mencionar que el proyecto de investigación "Atanasio D. Vázquez y la fotografía de la posrevolución en Veracruz", que recibió el apoyo del Instituto Veracruzano de Cultura en 2013, está en proceso bajo la coordinación de quien escribe el presente artículo.

${ }^{6}$ Cito la versión impresa en hoja suelta, sin número de página, anexada a Panchito Chapopote en 1928, y también reproducida en la edición facsimilar publicada por la Universidad Veracruzana en 1986.

7 Sobre la obra de Icaza, ver Beals (1931: 259-267), Brushwood (1986) y Rashkin (2007 y 2009: 203-222).

\section{Referencias bibliográficas}

Azuela, Mariano (1927), Los de abajo. Xalapa, Talleres Gráficos del Gobierno del Estado. 
Beals, Carleton (1931), Mexican Maze. Filadelfia y Londres, J.D. Lippincott.

Beals, Carleton (1934), Fire on the Andes. Filadelfia y Londres, J.D. Lippincott.

Brushwood, John (1986), "Las bases de vanguardismo en Xavier Icaza”. En Icaza, Xavier, Panchito Chapopote. Xalapa, Universidad Veracruzana.

Bustos Cerecedo, Miguel (1983), "Estridentistas en la sombra”. En Estridentismo. Memoria y valoración. México, Secretaría de Educación Pública, pp. 260-286.

De los Reyes, Aurelio (2000), Filmografía del cine mudo mexicano, vol. 3. México, Dirección General de Actividades Cinematográficas de la UNAM.

"Exhibición de películas" (1927), en ElDictamen. 4 de agosto de 2004 , p. 5.

Fuentes, Carlos (1999), Los años con Laura Díaz. México, Alfaguara.

Gallardo, Salvador (1925), El pentagrama eléctrico. Puebla, Casa Editora Germán List Arzubide.

Herrera,Celestino(1926a), "Educaciónfísica. El valoreducativo del deporte”. En Horizonte, núm. 5, agosto, pp. 39-40.

Herrera, Celestino (1926b), "La vida deportiva en Jalapa". En Horizonte, núm. 6, septiembre, pp. 37-39.

Horizonte (1926-1927). Xalapa, Talleres Gráficos del Gobierno del Estado. Edición facsimilar 201l. México, Fondo de Cultura Económica, Colección Revistas Literarias Modernas.

Icaza, Xavier (1926), Magnavoz 1926. Xalapa, Talleres Gráficos del Estado de Veracruz.

Icaza, Xavier (1928), Panchito Chapopote: retablo tropical o relación de un extraordinario sucedido de la heroica Veracruz grabados de Ramón Alva de la Canal. México, Cultura.

Jara, Heriberto (1986[1926]), "Informe que rinde el ejecutivo del estado ante la XXX Legislatura el 5 de mayo de 1926". En Blásquez Domínguez, Carmen (comp.), Estado de Veracruz. Informes de sus gobernadores, 1826-1986, t. 1l. Xalapa, Gobierno del Estado de Veracruz, pp. 5875-6012.

"Jira cinematográfica" (1927). En ElDictamen, 23 de julio de 1927, Veracruz, p. 5.

Liga Mexicana de Béisbol (2013), "Campeones en la historia de la Liga Mexicana", disponible en http:/ www.milb.com [consultado el 15 de octubre de 2013].
List Arzubide, Germán (1923), Esquina. México, Ediciones del Movimiento Estridentista/Librería Cicerón.

List Arzubide, Germán (1924), iiiMueran los gachupines!!! Puebla, Casa Editora Germán List Arzubide.

List Arzubide, Germán (1925), Plebe. Poemas de rebeldía. Puebla, Casa Editora Germán List Arzubide.

List Arzubide, Germán (1926a), "Construid un estadio. Mensaje a la provincia”. En Horizonte, abril de 1926, núm. 1, Xalapa, pp. 7-10.

List Arzubide, Germán(1926b), El viajero en el vértice. Puebla Casa Editora Germán List Arzubide.

List Arzubide, Germán (1926c), El movimiento estridentista. Xalapa, Ediciones de Horizonte.

List Arzubide, Germán (1927), Emiliano Zapata: exaltación. Xalapa, Gobierno del Estado de Veracruz.

List Arzubide, Germán (1928), Opiniones sobre el libro "El movimiento estridentista" de Germán List Arzubide. Xalapa, edición del autor.

List Arzubide, Germán (1967), El movimiento estridentista. México, Secretaría de Educación Pública.

López, Leticia (1998), Un suspiro fugaz de gasolina. Los murmullos estridentes de Salvador Gallardo Dávalos. Aguascalientes, Instituto Cultural de Aguascalientes.

Maples Arce, Manuel (1997), “Actual No. 1, Hoja de Vanguardia, Comprimido Estridentista de Manuel Maples Arce". En Luis Mario Schneider (comp.), El estridentismo o una literatura de la estrategia. México, Consejo Nacional para la Cultura y las Artes, pp. 267-275.

Maples Arce, Manuel (1922), Andamios interiores. Poemas radiográficos. México, Cultura.

Maples Arce, Manuel (1924), Urbe. Súper-poema bolchevique en 5 cantos. México, Andrés Botas e hijo.

Maples Arce, Manuel (1926), "Nuevas ideas. La estética del sidero-cemento". En Horizonte, junio de 1926, núm. 3, pp. 9-11.

Maples Arce, Manuel (1927a), El movimiento social en Veracruz. Xalapa, Talleres Gráficos del Gobierno del Estado.

Maples Arce, Manuel (1927b), Poemas interdictos. Xalapa, Ediciones de Horizonte.

Maples Arce, Manuel (1967), Soberana juventud. Madrid, Plenitud. 
Naveda Chávez-Hita, Adriana (1986), Imágenes de Xalapa a principios del siglo XX. Xalapa, Universidad Veracruzana.

Nieto, Rafael (1927), El imperio de los Estados Unidos y otros ensayos. Xalapa, Talleres Gráficos del Gobierno del Estado.

"Nuevo Secretario General de Gobierno" (1926), en El Dictamen, 7 de enero de 1926, Veracruz, p. 3.

Ortiz Escobar, Roberto (2001), "El cine mexicano filmado en Veracruz". En De la Vega Alfaro. Eduardo (coord.) Microhistorias de cine en México. Guadalajara y México, Universidad de Guadalajara/UNAM/IMCINE/ Cineteca Nacional/ Instituto Mora, pp. 297-314.

Quintanilla, Luis (Kyn Taniya) (1923), Avión. México, Cultura.

Quintanilla, Luis (Kyn Taniya) (1924a), Radio. Poema inalámbrico en trece mensajes. México, Cultura.

Quintanilla, Luis (Kyn Taniya) (1924b), Teatro Mexicano del Murciélago (programa). México, Talleres Gráficos de la Nación.

Rashkin, Elissa (2007), "The X in Mexico: Xavier Icaza and the Literature of the Revolution". En Hipertexto, invierno, núm. 5. Edinburgh, Texas, University of Texas Pan-American. Disponible en http://www. utpa.edu/dept/modlang/hipertexto/hiper5indice.htm [consultado el 10 de octubre de 2013].

Rashkin, Elissa (2009), The Stridentist Movement in Mexico: The Avant-Garde and Cultural Change in the 1920s. Lanham, MD, Lexington Books/Rowman and Littlefield.

Schneider, Luis Mario (1997), El estridentismo o una literatura de la estrategia. México, Consejo Nacional para la Cultura y las Artes.

Turrent Rozas, Lorenzo (1973), Obra completa, Miguel Bustos Cerecedo (comp.). Xalapa, Universidad Veracruzana.

Vela, Arqueles (1922), La señorita Etcétera, novela semanal de El Universal Ilustrado, 14 de diciembre, México.

Vela, Arqueles (1926), El Caféde Nadie. Xalapa, Ediciones de Horizonte.

Wilkie, James, y Edna Monzón Wilkie (2001), Frente a la Revolución mexicana: 17 protagonistas de la etapa constructivista, t. 2. México, Universidad Autónoma Metropolitana. 